\title{
Growth and hierarchy of cities in Algeria: Application of the Rank-Size rule
}

\author{
Ahmed Bousmaha ${ }^{1,}{ }^{*}$, Salah Zeraib ${ }^{2}$, Nassira Benhassine ${ }^{3}$ and Yacine Kouba ${ }^{4}$ \\ 1 Department of geography and regional planning, University of Oum El Bouaghi 04000 Oum el Bouaghi, \\ Algeria; ahmed.bousmaha@univ-oeb.dz \\ 2 Department of geography and regional planning University of Batna 2; 05000 Batna, Algeria ; zeraibsa- \\ la@yahoo.fr \\ 3 Department of architecture, University of Constantine 3, Salah Boubnider 25000 Constantine, Algeria; nas- \\ sira.benhassine@univ-constantine3.dz \\ 4 Department of geography and regional planning, University of Oum El Bouaghi, 04000 Oum el Bouaghi, \\ Algeria; yacinoargelino@gmail.com \\ * Correspondence: ahmed.bousmaha@univ-oeb.dz
}

\begin{abstract}
The objectives of this paper are to analyze the urban growth and urbanization phenomenon in Algeria. Two processes that originated respectively by the expansion of existing urban areas and the process of urbanization that took place between 1954 and 2008, a period marked by significant economic, social and political changes in Algerian society. Our analysis was mainly based on the Algerian general census of population and habitat (2008) and on the application of rank-size distribution of cities according to Zipf's rule. This study revealed that in Algeria, the urban system is particularly marked by the dramatic expansion of small cities. Indeed, the development of small towns, through the transition from rural to urban and the residential loosening of large cities have influenced the trend towards the balance of the urban system in Algeria. Results revealed also how the "primatial" city is undergoing profound economic and social changes at the national level. These changes are most often imposed from the top as part of land-use planning policy. This study provides some insights into the demographic dynamics of cities and the evolution of urban hierarchies in Algeria, through the comparison of the different rank-size distributions of Algerian cities in space and time. Our results suggest that land-use planning strategies are the only policies capable of influencing the future of the Algerian urban system.
\end{abstract}

Keywords: urbanization; urban growth urban hierarchy; urban system.

\section{Introduction}

The economic and social transformations that Algeria has experienced in recent decades have led to significant changes in the geographical distribution of its populations [1]. The demographic transition from a traditional rural to a modern urban society is considered as the most striking fact. The urbanization movement has significantly strengthened in conjunction with administrative promotions and industrial settlements throughout the country. Overall, the outlines of the regional urban framework have been drawn since independence; they perfectly fit the structure of the colonial spatial organization. The French relied on port cities to facilitate exports to the Metropolis. The coastline represents fundamentally different characters from that of other regions in both the composition and the prioritization of the urban centers. It is dominated by the development of the biggest city of Algiers and other coastal big cities such as Oran (Western Metropolis), Annaba (Eastern Metropolis) and Constantine (Inland Metropolis). From 1966 to 2008, the urban structure was enriched by several centers, nevertheless it presents the 
same spatial disparities and opposes well-urbanized and organized regions against delayed and poorly urbanized ones.

The phenomenon of urbanization in Algeria is relatively recent and is characterized by its very rapid growth and deep disparities in its spatial arrangement. Algeria, has an ancient urban tradition and is experiencing an accelerated urbanization process, with a scale unsurpassed for several decades.

As Marc Côte [2] pointed out "Although very old by its roots, urbanization in Algeria appears to be very recent in its magnitude" and adds that, for several decades, this process has taken the form of an urban explosion that has upset landscapes, mentalities and the society itself. Every time, the urbanization process was depending on the economic context and was often triggered by historical or economic events and it took place on different spatial-temporal sequences [3]. Thus, the history of urbanization in Algeria has been made up of a series of successions and ruptures corresponding to the multiple occupations of the country from antiquity to the present day [4]. Today, the urbanization movement is marked mainly by the extraordinary rise of micro-urbanization (i.e., small towns).

In this study we analyze the urban growth and the phenomenon of urbanization which is originated by the expansion of the stratum of the existing urban centers or by the switching from rural to urban between 1962 and 2008, a period marked by significant economic, social and political changes. Our analysis is mainly based on the general census of population and housing of Algeria and the application of city rang-size distribution criterion according to Zipf's low. The study of urban hierarchies and their evolution occupies an important place in contemporary regional planning. In this context, the objective of this paper is to analyze the demographic evolutions of the Algerian cities during a time sequence long enough to describe the characteristics of Algeria's city system and the evolution of urban hierarchies. Finally, we will summarize the results achieved and discuss the lessons that can be learned in terms of land use policies.

\section{Materials and Methods}

The rang-size distribution of cities is used for the study of cities or population centers in a geographical area according to a Cartesian diagram with ranks on the $\mathrm{x}$-axis and sizes on the $y$-axis [5]. The units considered are generally arranged according to a more or less extended or concave curve [6]. The size of cities, measured by their population is an indicator of their importance, which must however be supplemented by other measures when extending the comparison to cities in countries of unequal economic development. Measuring the population of a city is tricky because of the difficulties of delimiting urban entities, which expand spatially at the same time as their number of inhabitants increases [6]. While administrative, industrial, commercial and service functions are highly representative of the attractive powers of cities, the urban population remains one of the most synthetic parameters of the measurement of urban fact [7].

The harmonized statistics of the GEOPOLIS global database also give a very high primacy index in the vast majority of countries. By looking more closely at statistics, it appears that when two countries have a comparable urban population, the demographic size of their capital is often also very close [8].

Zipf's law, known as the rank-size law, allows for a synthesis of the distribution of cities according to their demographic sizes [9-11]. This law is "one of the most striking facts in the social sciences in general [12]. Urban hierarchy has often been analyzed on the basis of the Rang-Size low, often known by Zipf's Law, which has shown that the forces 
of spatial organization of concentration-dispersal act in such a way that the size of cities $(\mathrm{P})$ is distributed regularly according to their rank ( $\mathrm{r}$ ) according to the relationship [13]:

$\mathrm{P}=\mathrm{b} \times \mathrm{ra}$

where $\mathrm{a}$ and $\mathrm{b}$ are parameters that vary depending on spaces and periods

For Thouez [14] when the angular coefficient of the linear fit is equal to 1 , it leads to a very simple expression of Zipf's law.

$\mathrm{Pn}=\mathrm{P} 1 / \mathrm{Rn}$

Where $\mathrm{P}$ and $\mathrm{R}$ area population size and rank, respectively.

According to the latter formula, it is enough to know the population of the first city to immediately deduce the size of all other cities and the total urban population. The population of $\mathrm{n}$ cities with more than 1000 inhabitants is by definition:

Or:

$$
\mathrm{PT}=\mathrm{P} 1+\mathrm{P} 2+\mathrm{P} 3+\ldots+\mathrm{Pn}
$$

Or even: $\mathrm{PT}=\mathrm{P} 1(1+1 / 2+1 / 3+\ldots+1 / \mathrm{n})$

To visualize Zipf's law, cities are ranked by population number and a graph of the logarithm of the ranks on the $\mathrm{x}$-axis and the logarithm of the populations on the $y$-axis which generates a straight line whose slope is close to $(-1)$. The rank one city will have a population (size) twice that of the rank two city. The observation is first empirical and the interpretation of the observed regularity has been proposed in hindsight, intuitively [15] as emanating from a balance between agglomeration and dispersal forces [16] The city is a node in a hierarchical network of relationships, it is then defined by its relative position in a complex hierarchy of productive, social and territorial functions operating at regional or national levels [17].

Numerous indices can be used to measure primacy, ranging from the ratio to the second city (Jefferson index), to the next three cities (Stewart index), or even several other cities $[18,19]$. In this context and to assess the degree of urban concentration in Algeria, we used the following indicators: the part of the largest city of the frame in the urban population (Prim), the share of the first city in the total population or the ratio of the largest city to the second city (Jefferson index), or to the next three cities (Stewart index), or to several other cities (Rosen and Resnick index). The first city is often taken as the basic reference for analyzing the theoretical distribution of city size or for plotting the theoretical straight line. According to [20], all other cities are determined according to this primatial city, while the straight line originates from P1. It turns out that the first city is itself, the product of the urban system and the central paradigm of the Zipf's law is this distribution of cities within the urban system and the hierarchical relationship that connects the different urban centers. He adds that often the gap between the first city and the other cities is so large and tenacious that it contributes to completely distorting the entire urban system. This gap is not only demographic, it is also economic, political, social, cultural and spatial.

The share of the first city in the urban population is a good indicator of primacy. This simple indicator has the merit of expressing the weight of the primatial city in relation to the entire urban system: $\mathrm{p} 1=\mathrm{P} 1 / \Sigma \mathrm{P}$.

The ratio between the real population (P1) and the theoretical population (b) of the first city: $\mathrm{p} 2=\mathrm{P} 1 / \mathrm{b}$ 
This ratio is all the more high since primacy is pronounced. The unit means regularity while values greater and lower than 1 indicate primacy and compacting summit, respectively.

The ratio of the difference between the observed (P1) and theoretical (b) sizes to the theoretical size of the first city: $\mathrm{p} 3=(\mathrm{P} 1-\mathrm{b}) / \mathrm{b}$ or $\mathrm{p} 3=\mathrm{P} 1 / \mathrm{b}-1=\mathrm{p} 2-1$.

This index is null when the theoretical size is equal to the real size. It is negative when the real size is smaller than the theoretical size. The extreme value is reached when all cities are equal. It is positive when all cities are equal, and the maximum value is reached when most of the urban population is concentrated in the first city. The primacy index is the ratio between the two largest cities. This primacy index can be equal to the macrocephaly index when the highest ratio between two successive cities in the hierarchy is between the 1st and 2nd city. In this case, the higher the value of the index, the more it corresponds to that of hierarchical organizations of polarized systems of cities. A low primacy index, lower than the macrocephaly index, may indicate bipolar, multipolar or even homogeneous organizations.

\section{Results}

\subsection{Urban growth and transition from rural to urban in Algeria}

The urbanization rate increased modestly during the colonial period (between 1886-1954) rising from $13.9 \%$ to $25 \%$ in 1954 (an increase of 11.1 percent in 68 years). After independence, the rate increased from 31.4\% in 1966 to $65.94 \%$ in 2008 (an increase of 34.5 percent in 42 years). In other words, Algeria was a $75 \%$ rural society in 1954 and has undergone a demographic transition by gradually moving to a predominantly urban society with an urbanization rate of $65.9 \%$ in 2008 [21] (Figure 1). This figure highlights 1987 as a year during which rural and urban populations became balanced, with 11.5 million inhabitants each.

The originality of this urbanization lies in the sprawling of the existing urban cities or is due to the process of urbanization [22]. This urbanization movement is mainly marked by the extraordinary growth of small towns [23]. The effort to modernize the country (i.e., vigorous industrialization process, expansion of the role of the state and densification of the administrative framework, regional planning policy and actions) has mainly benefited the small and medium-sized cities located in the inner country with a view to reducing the strong polarization on the coastline and establishing socio-spatial justice. Since then, these agglomerations have experienced rapid growth due to the accumulation of industrial, service and investments. Figure 1 shows that the rural population continues to grow despite the assertion of their desertion.

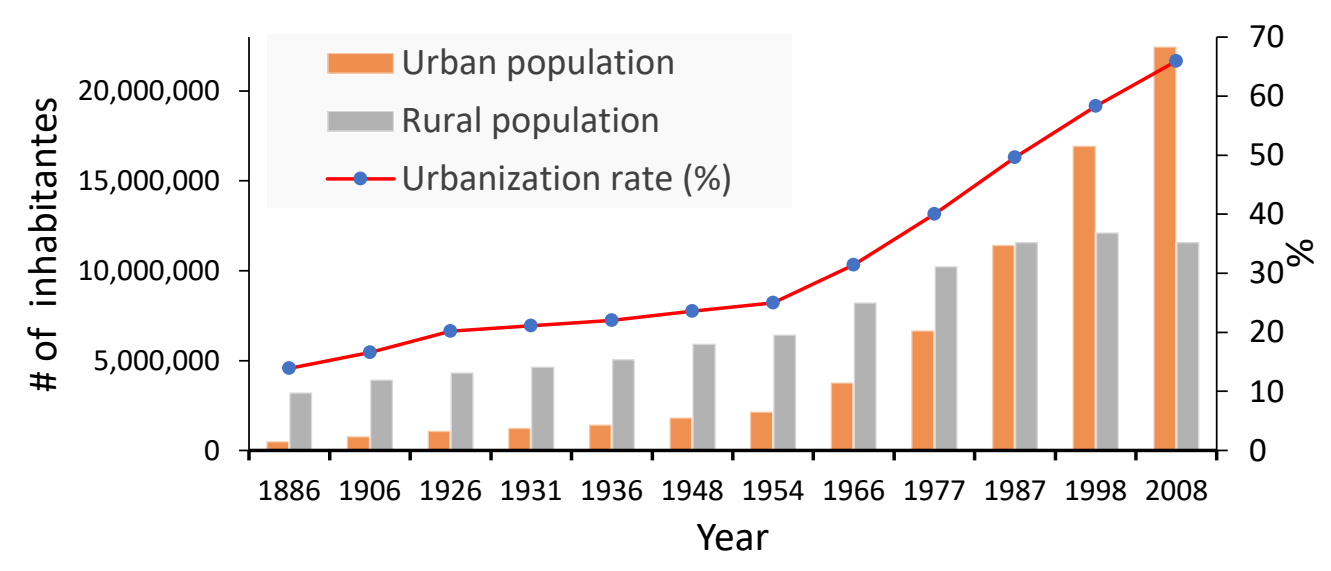

Figure 1. Evolution of urban and rural population in Algeria from 1886 to 2008 as well as the progression of the urbanization rates in that period 


\subsection{The uneven spatial spread of urban reality}

In Algeria the urban structure often shows a disparity over the territory which is related on one hand to the diversity of physical environments and on the other hand to the legacies of French colonization and the development policy implemented since the independence. Indeed, urbanization in Algeria is far from being a homogeneous process, its history is made up of sequences of successions and breaks corresponding to various occupations of the country from antiquity to the present day [4].

Colonial urbanization was completely oriented towards the metropolis, reinforced by roads network and the totally extroverted activities which led to the emergence of the very accentuated littoralization profile (i.e., coastal overdevelopment effect that is the process of population and activities being concentrated on the coasts) of the Algerian space. Indeed, the data in Table 2 clearly illustrate the unequal distribution of populations and confirm the phenomenon of littoralization in Algeria.

Table 1. Changes in population and density across the three major sets of Algerian physical space

\begin{tabular}{|c|c|c|c|c|c|c|c|}
\hline \multirow[t]{2}{*}{ Physical space } & \multirow{2}{*}{$\begin{array}{l}\text { Surface } \\
\text { area } \\
\left(\mathrm{km}^{2}\right) \\
\end{array}$} & \multicolumn{3}{|c|}{ Population (thousands) } & \multicolumn{3}{|c|}{ Density inhabitants $/ \mathrm{km}^{2}$} \\
\hline & & 1987 & 1998 & 2008 & 1987 & 1998 & 2008 \\
\hline Coastal strip & $\begin{array}{l}45000 \\
(1.9 \%)\end{array}$ & $\begin{array}{l}8904 \\
(38.6 \%)\end{array}$ & $\begin{array}{l}11000 \\
(37.8 \%)\end{array}$ & $\begin{array}{l}12342 \\
(36.2 \%)\end{array}$ & 197.8 & 244.4 & 274 \\
\hline $\begin{array}{l}\text { Tell and } \\
\text { steppe }\end{array}$ & $\begin{array}{l}255000 \\
(10.7 \%)\end{array}$ & $\begin{array}{l}12145 \\
(52.7 \%)\end{array}$ & $\begin{array}{l}15300 \\
(52.6 \%)\end{array}$ & $\begin{array}{l}18010 \\
(52.9 \%)\end{array}$ & 47.6 & 60 & 70.6 \\
\hline Sahara & $\begin{array}{l}2081000 \\
(87.3 \%)\end{array}$ & $\begin{array}{l}2002 \\
(8.7 \%)\end{array}$ & $\begin{array}{l}2801 \\
(9.6 \%)\end{array}$ & $\begin{array}{l}3728 \\
(10.9 \%)\end{array}$ & 0.96 & 1.35 & 1.8 \\
\hline Whole country & 2381741 & 23051 & 29113 & 34080 & 9.7 & 12.2 & 14.3 \\
\hline
\end{tabular}

After independence, the concentration of activities and population on the coastal fringe reinforced the phenomenon of littoralization especially during the 1970s following the policy of the "industrial industry" initiated by the authorities of that time. Several factors explain this phenomenon of littoralization including the devaluation of agriculture which has caused a massive exodus of rural population to the literal on the one hand, and on the other hand, the development of the coastal zone has encouraged the concentration of urban sprawl on limited areas and thus creating the conditions for the emergence of cities with a linear corridor on the coastal strip. Which has led to a regional imbalance between the North and the rest of the country? In line with this, Rahmani [4] pointed out that in the Maghreb; it is essentially the regional differences and disparities which are becoming pathological in the most deprived regions where they are perceived as such. In these conditions, it is real antinomies in lifestyles in a heterogeneous and disarticulated Maghreb space [4]. These territorial distortions were then the main concern of the land-use planning policy. The preponderance of the big coastal cities has been followed by a rebalancing in favour of small and medium-sized cities in the inner country. The diversity of regional situations and geographical constraints explain the heterogeneity of urban structure. 


\subsection{Evolution of the urban structure in Algeria}

The study of urban structure remains a good mean of empirical analysis and allows the distribution of localities in a region or country within preconceived demographic thresholds, is at this level that the field of threshold research is truncated. A threshold is a break between two systems; it characterizes the transition from one structure to another. Nevertheless, this threshold can change direction depending on the evolution of space. It is at this level that we need to orient ourselves using deductive means to determine or search for boundaries between the different strata[3].

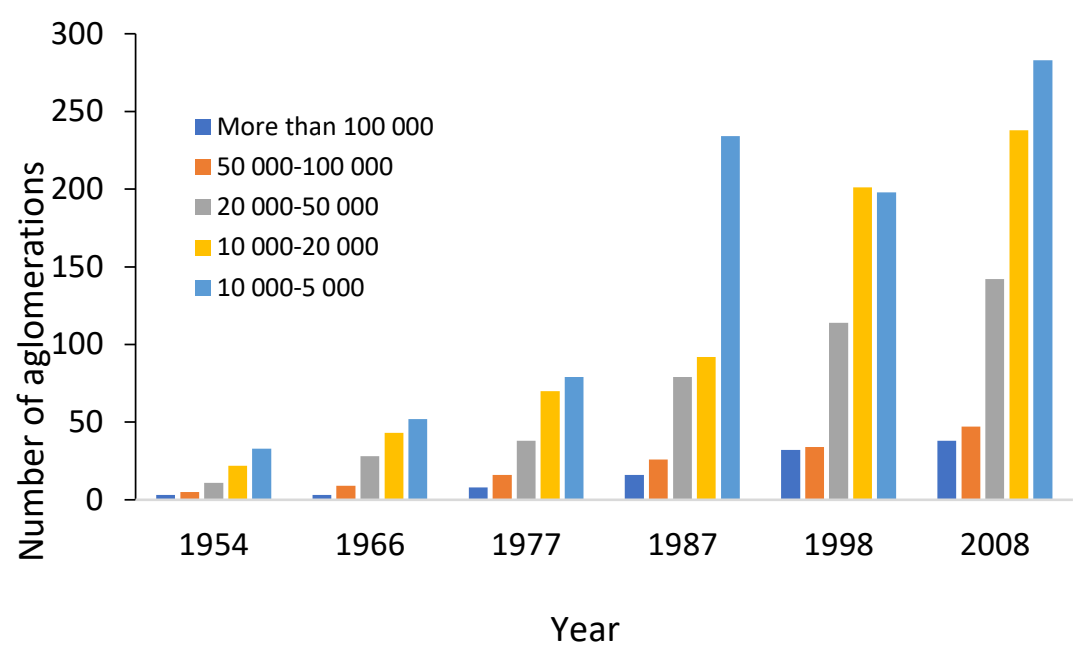

Figure 2. Evolution of the number of agglomerations by size classes (i.e., number of inhabitants) in Algeria from 1954 to 2008

Figure 2 shows that the evolution of urban units has been gradual since 1954. But the most significant fact is the overwhelming weight of the number of small towns with $88 \%$ of the total, while large and medium-sized cities; they represented consecutively $5.08 \%$ and $6.28 \%$ in 2008 .

\subsection{The intensification of the urban frame through the transition from rural to urban}

Our analysis of a sufficiently long period shows that significant changes have occurred in the urban population in Algeria (Figure 2). Among the 748 urban cities registered in 2008, 674 were rural settlements in 1954 which represent more than $90 \%$ of the total. In detail, the transition from rural to urban has been done in the following way (Figure 3): (1) Algeria had 74 urban settlements in 1954, (2) 62 rural settlements in 1954 became urban in 1966, (3) 75 rural settlements in 1966 became urban in 1977, (4) 236 rural settlements in 1977 became urban in1987, (5) 132 rural settlements in 1987 became urban in 1998, and (6)169 rural settlements in 1998 became urban in 2008. 


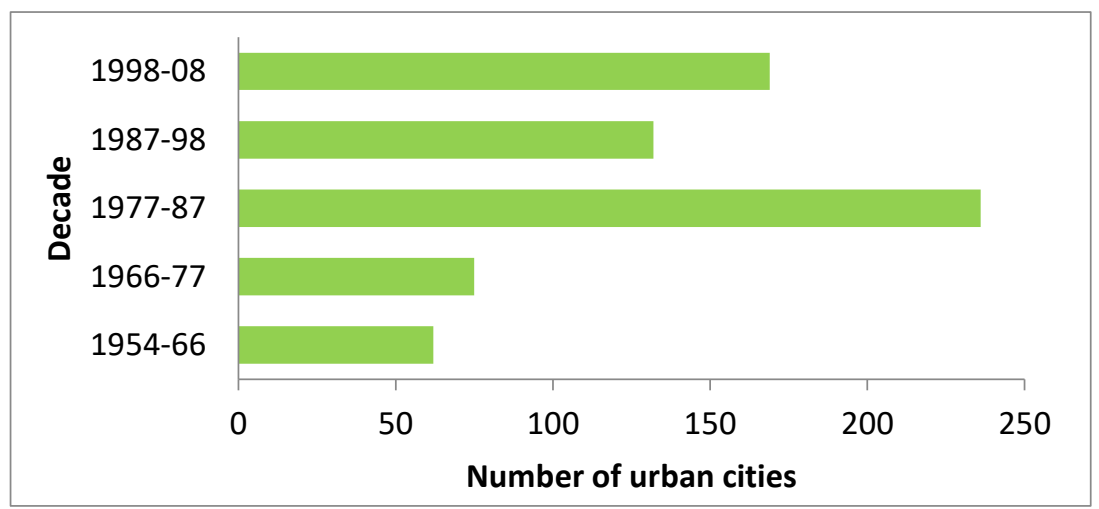

Figure 3. The number of rural settlements switched to urban cities in each decade during the period 1954-2008 in Algeria

The Algerian urban structure has been enriched by 35 large cities ( $\geq 100$ thousand inhabitants), 42 medium-sized towns (between 50,000 and 100,000 inhabitants), 121 small towns (between 20,000 and 50,000 inhabitants) and 464 urban settlements (between 5,000 and 50,000 inhabitants). These data confirm that the originality of the Algerian urban network lies in the predominant place occupied by small towns. In 2008, small towns accounted for more than $80 \%$ of the urban frame compared with $72.93 \%$ in 1987 and $70.61 \%$ in 1977. Thus, the emergence of small towns (by transition from rural to urban) is an important component of urban growth in Algeria.
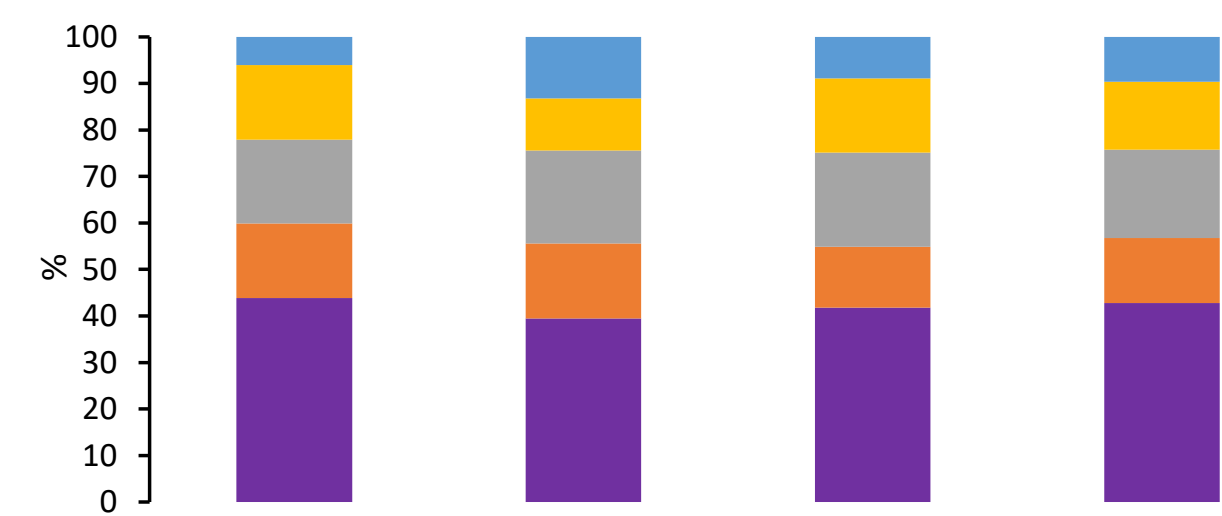

1977

1987

1998

2008

More than 1000000

50 000-100 000

$20000-50000$

$10000-20000$

Less than 10000

Figure 4. Repartition of the total population by category of urban cities (urban cities were classified based on their size) 
According to Figure 4, the contribution of large cities to the total population has gradually decreased from $44 \%$ in 1977 to $41.8 \%$ in 1998, then it started to rise slightly $(42.74 \%)$ again in the last census of 2008. However, the number of inhabitants that live in large cities boosted sharply, it increased from 2,935,461 in 1977 to 9,604,736 in 2008 which means a gain of $6,669,275$. The weight of medium-sized cities has sat around $16 \%$. Nevertheless, the number of inhabitants that live in this city-class raised from 1,071,270 inhabitants in 1977 to 3,151,727 inhabitants in 2008 (a gain of 2,080,457 inhabitants). The weight of small towns increased sharply from $40 \%$ in 1977 to 47.6 in 1998 and then declined slightly to $43.23 \%$ in 2008 . The number of inhabitants living in small towns rose from 2,680,054 in 1977 to 9,714,716 in 2008, a gain of 7,034,662. Thus, small cities, by their number and demographic weight, constitute an important component of urban growth in Algeria.

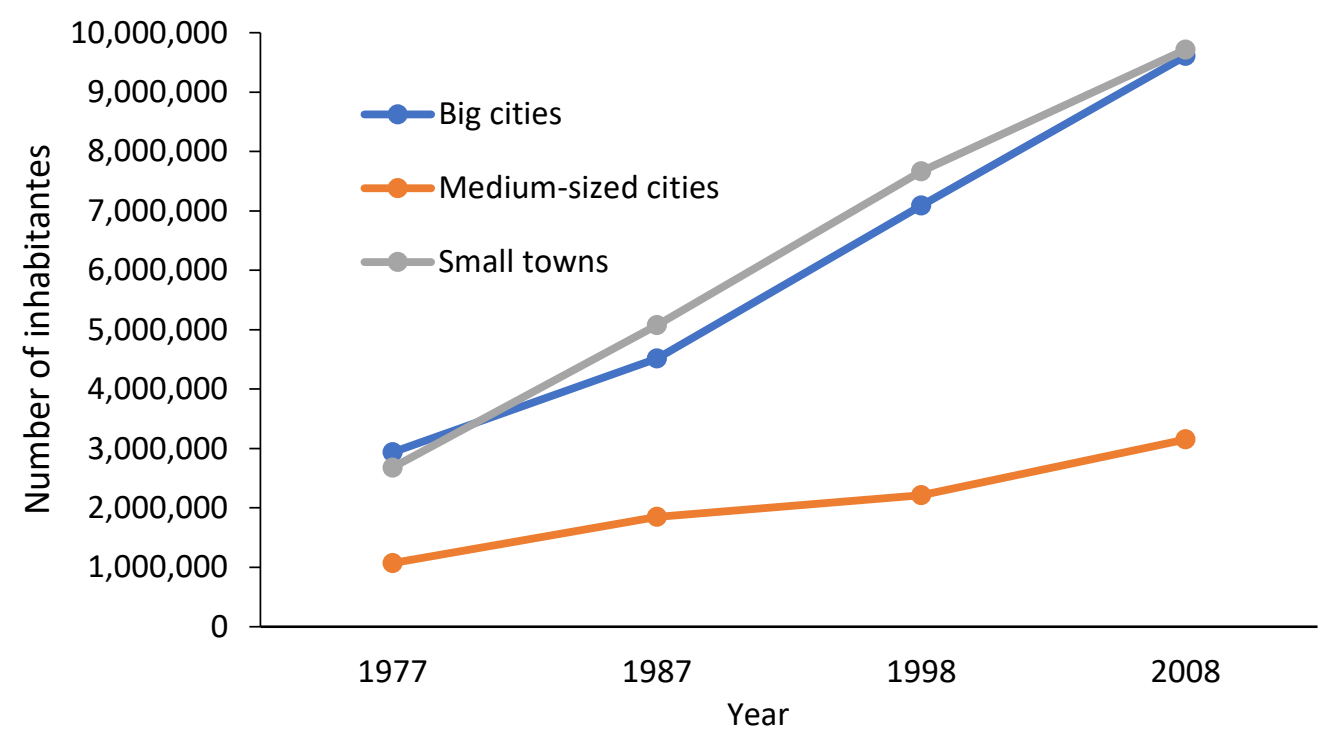

Figure 5. Evolution of the urban population by category of cities from 1977 to 2008

In terms of population, all intercensal periods have indicated an increase in the urban population, notably through the transition from rural settlements to urban areas. In this context, as the results confirm, rapid urbanization is a recent phenomenon, despite the very old urban phenomenon, marked by the transition of a large number of rural settlements to the rank of urban areas and the shift of several urban centers to the higher rank during the different periods of the census. Endogenous and exogenous factors are at the root of this urbanization movement. The administrative transformation of a secondary urban center to a municipality gives it political and administrative functions that often generate economic benefits. As Côte [24] pointed out "All the efforts of socialism-states on the secondary and tertiary sectors are in the direction of rapid urbanization". This urbanization is marked by the passage of a significant number of rural settlements into the category of urban agglomerations and is also due to the change in qualification and administrative rank of some localities following the administrative reforms of 1974 and 1984 and the process of industrialization. Thus, the originality of this urbanization, as Prenant [22] pointed out, lies in the expansion of the stratum of the existing urban centers or in the process of urbanization. The role of the state has been decisive in the emergence and affirmation of these cities [25]. The main form of urban growth in Algeria is mainly linked to the development of the urban network. From 74 urban centers in 1954 to 136 in 1966 and 211 in 1977, 447 in 1987, then 579 cities in 1998 and 748 
town in 2008 (i.e., the number of urban centers increased tenfold between 1954 and 2008). Nevertheless, the existence of a seedling of small towns is one of the most striking features of urbanization in Algeria. The emergence of small towns (by switching from rural to urban) is an important component of urban growth in Algeria. The context in which urbanization and urban growth have taken place strongly marks the urban system in its configuration, hierarchy and spatial distribution of its elements.

\subsection{Rank-size distribution of Algerian cities according to Zipf's law}

The Jefferson Index increased from 2.23 in 1998 to 2.94 in 2008. The population of the city of Algiers was 2364230 in 2008, while that of Oran was only 803329, making it almost three times more populated than the second largest city in the urban system. As for the Stewart index, it indicates a clear drop in the cities that are directly behind Algiers in the urban structure (Oran, Constantine and Annaba). The empirical results of a rank-size analysis depend in the first place on the nature of the entities that are observed, the set that is considered, and the way in which the respective sizes of the entities are measured.

Table 2. Evolution of Primacy indices (calculated for Algeria) from 1954 to 2008

\begin{tabular}{|c|c|c|c|c|c|c|}
\hline Indicator & 1954 & 1966 & 1977 & 1987 & 1998 & 2008 \\
\hline Urban population $\Sigma \mathrm{PU}$ & 2157938 & 3778482 & 6686785 & 11444249 & 16966937 & 22471179 \\
\hline Total population $\Sigma \mathrm{PT}$ & 8614704 & 12022000 & 16948000 & 23038942 & 29100863 & 34080030 \\
\hline Prim & & & & & & \\
\hline $\mathrm{p} 1=\mathrm{P} 1 / \Sigma \mathrm{PU}$ & 27.6 & 24.97 & 20.25 & 13.17 & 9.25 & 10.61 \\
\hline $\begin{array}{l}\text { Algiers' share of the total } \\
\text { population }(\%)\end{array}$ & & & & & & \\
\hline $\mathrm{P} 1 / \Sigma \mathrm{PTx} 100$ & 6.91 & 7.85 & 7.99 & 6.54 & 5.39 & 6.53 \\
\hline $\begin{array}{l}\text { The weight of the } 4 \text { largest } \\
\text { cities in relation to the total } \\
\text { urban population (\%) }\end{array}$ & & & & & & \\
\hline Prim $4=\mathrm{P} 1+\mathrm{P} 2+\mathrm{P} 3+\mathrm{P} 4 / \Sigma \mathrm{P}$ & 51.45 & 44.44 & 36.55 & 25.18 & 21.4 & 17.61 \\
\hline Jefferson $\quad$ Index $\quad(\mathrm{Ij})$ & & & & & & \\
\hline $\mathrm{j}=\mathrm{P} 1 / \mathrm{P} 2$ & 2.1 & 2.88 & 2.73 & 2.4 & 2.23 & 2.94 \\
\hline Stewart $\quad$ Index & & & & & & \\
\hline $\mathrm{s}=\mathrm{P} 1 /(\mathrm{P} 2+\mathrm{P} 3+\mathrm{P} 4)$ & 1.16 & 1.28 & 1.24 & 1.1 & 1.03 & 1.48 \\
\hline
\end{tabular}

\section{Discussion}

In Algeria, the portion of the first city in the urban population is a good index to measure primacy. This simple indicator expresses the weight of the primatial city in relation to the entire urban system: $\mathrm{p} 1=\mathrm{P} 1 / \odot \mathrm{P}$. It is equal to 0.10 for Algiers, i.e., $10.61 \%$ of the urban population resided in Algiers in 2008. According to the data in Table 2, the primacy indicators tend to increase, indicating a widening gap between the capital and other cities, which can be explained by the following factors: The expansion of the agglomeration of Algiers has extended to include a certain number of adjoining agglomerations, the second city, Oran, has continued to grow at a low average annual rate and the third and fourth cities (Constantine and Annaba) have recorded negative or low growth 
rates respectively, with in particular the transfer of population surpluses to other agglomerations or even to new cities such as Ali Mendjelli in the case of Constantine [26]. Moreover, not only the first city is concerned by primatiality but also those cities with sizes deviate too far from the cities that succeed them, as is the case of the regional metropolises Oran, Constantine and Annaba This is also the case when studying regional urban systems where some cities benefit from indisputable primacies often overwhelming other cities in the region. Most of main towns of the wilayas (provinces) take over the entire command and territorial control apparatus of the wilaya, replicating the national model of the capital.

The analysis of the Algerian urban system since independence on the basis of the Zipf's law allowed us to measure its various parameters. The results show that the capital Algiers has been a primatial city since 1954, despite the emergence of medium-sized cities and a proliferation of small towns. The Capital Algiers stands out from the rest of the cities and presents itself as a primatial city whose weight is predominant in the whole urban system. This situation can be explained by the strong polarization of the Algerian space

The macrocephaly index is the highest population ratio between two successive cities in population arrangement. It is necessary to know not only the value of this ratio but also the ranks of the two successive cities producing this ratio.

- When a high ratio is measured between the two largest cities in the distribution, the system is primatial.

- When this high ratio is measured between the 2nd and 3rd cities, the system is bicephalous.

- When a high ratio is measured further down the distribution, the system is multipolar or polycentric.

- When the ratio is relatively low and the cities used for its measurement are far apart in the arrangement, the system is homogeneous or hierarchical.

The cities at the top of the hierarchy show a deficit with the exception of Algiers. The gaps between cities in this stratum and the fitted line are increasing, their observed population is lower than the theoretical population required by the model. Thus, the large cities with a population of over 150000 inhabitants, and comprising 21 agglomerations (from the 2nd to the 22nd rank) are under-represented in relation to the overall distribution. On the other hand, cities with a population between 10000 and 150000 inhabitants, their real population is higher than the theoretical population. Small urban agglomerations with a population between 5000 and 10000 also show convexity, with agglomerations belonging to this size category being under the fitted line. This situation means that the urban system is being reinforced by small and medium-sized cities. It can be said also that small and medium-sized towns (10000-15000 inhabitants) are an essential part of the Algerian urban frame, they are considered as basic cogs and play a fundamental role in the regional balance.

The hierarchical curve of Algerian cities shows a convexity at the level of small towns. This convexity expresses the inflammation of the small towns whose number is relatively high compared to the whole urban system, as we have shown previously. The importance of small towns is linked to a process of urban growth that is largely achieved from the bottom. It is the small cities that are experiencing the highest rates of growth.

The study of the city system according to the two fundamental principles of hierarchical organization: the so-called "market principle" and the principle of administra- 
tive hierarchy. They determine hierarchical city networks. The models of hierarchical organization known as "a-spatial", according to Kaddouri [27] are then always spatialized by the integration of neighborhood or proximity constraints (spatial constraints).

The Algerian urban system corresponds to a macrocephalic system because there is a very pronounced gap between the first city (Algiers) and directly lower hierarchical levels. For several decades, urban development actions have been characterized by the implementation of programs related to the reconstruction of the country and the satisfaction of the people's essential needs in terms of housing, equipment and infrastructure. These actions have fostered urban dynamics and more particularly the multiplication of urban units. The change in the number of urban units depends on the reclassification process that requires a long time to reach the top ranks of the hierarchy. With this new form of distribution, it is clear that the Algerian urban system has a wide range of small urban units that could contain, in the long run, more populations than large urban units [26]. Despite legislation promoting the protection and preservation of agricultural land, urban and peri-urban agriculture seems to be little taken into account in the implementation of urban planning tools in our case study. Even though the development policies are struggling to influence the consumption of peri-urban agricultural spaces, coastal agricultural land is the most affected, as it is the site of multiple socio-spatial transformations [28].

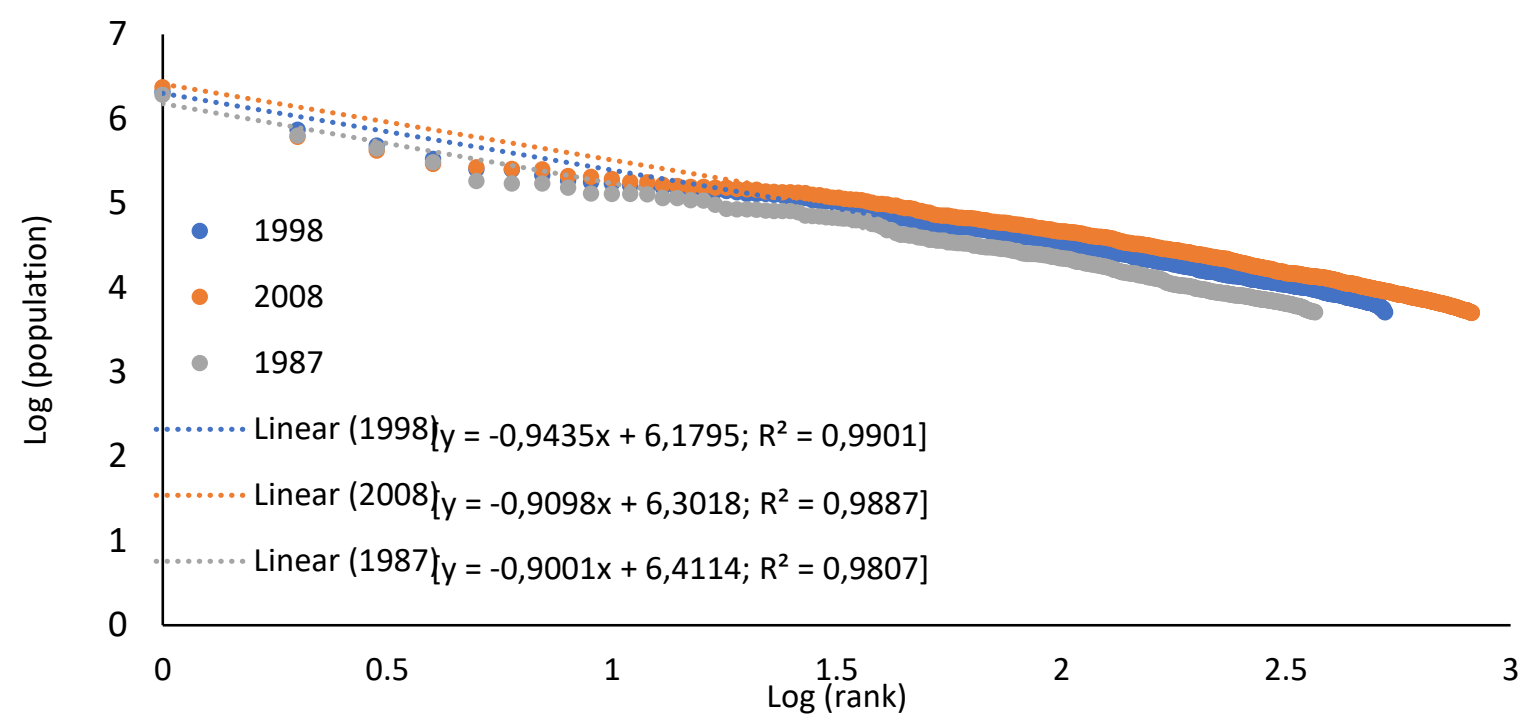

Figure 6. Hierarchical distribution of cities with more than 5000 inhabitants in Algeria during 1987,1989 and 2008

\section{Conclusions}

The results of this study show that Algeria's urban primacy rate, i.e., the weight of the population of the country's largest city relative to the population of other cities, increased until the 1990s and then declined systematically, meaning that Algiers' demographic dynamism is fading to the benefit of other cities. Algiers remains a real hub for Algeria's external trade. However, it should be stressed that it is first of all the idea of permanence that emerges: permanence of the hypertrophy of the agglomeration of Algiers and permanence of imbalances between regions where urban reality remains marginal and whose triggering factors are historical (i.e., the legacies of colonization), natural (i.e., diversity of the physical environment and spatial duality plains/mountains), or political (i.e., unequal distribution of public investments). The application of Zipf's law showed the imbalance of the Algerian urban system. The primatial city (Algiers) is un- 
questionably hegemonic in the national territory which it commands as a capital. The urban growth model in Algeria is akin to a stochastic process that depends in particular on randomly distributed exogenous factors. In this model, the sizes of cities tend, in a stationary state, towards a distribution that follows Zipf's law, i.e., a distribution of Pareto with a hierarchical coefficient equal to 1.

The strengthening of dominating and draining powers of the coastal urban axis and the proliferation of small cities mark the limits of regional integration policy and includes the social and spatial imbalances of national construction. The observation of the demography of Algerian cities and a more elaborate analysis of the evolutions of urban hierarchies over the last three decades encourages us to challenge this overly strict view of urban dynamics and at the same time to shift the "cursor" to the priorities for better urban planning. The future of urban structure in Algeria is conditioned by the adopted territory planning policy.

\section{References}

1. Kateb, K. Population et organisation de l'espace en Algérie. L'Espace géographique, 2003, 32(4), 311-331.

2. Côte, M. L'espace algérien, les prémices d'un aménagement OPU. Alger, 1993, 278p.

3. Raham, Dj. Les Structures Spatiales de l'Est Algérien. Les maillages territoriaux, urbains et routiers (Doctoral dissertation, Université de Constantine), 2001.

4. Rahmani, A.B.; La croissance urbaine en Algérie, coût de l'urbanisation et politique foncière. Alger, Ed. OPU, 1982.

5. Zipf, G. Human behavior and the principles of least effort. Cambridge. Mass. Addinson Wesley Press. Cambridge, 1949.

6. Pumain, D. L'invention permanente: la hiérarchie urbaine». Bridel P.(éd.), L'invention dans les sciences humaines. Hommage à Giovanni Busino, Genève-Paris, Labor et Fides, 2003 ? 66-86.

7. Moriconi-Ebrard, F. Géopolis: pour comparer les villes du monde. Anthropos: Economica [diff.].1994.

8. Moriconi-Ebrard, F. Un modèle pour la croissance des systèmes urbains, la loi de la métropolisation/A growth model for urban systems, the metropolitan concentration law. Géocarrefour, 1998 ? 73(1), 55-70.

9. Guérin-Pace, F. Rank-size distribution and the process of urban growth. Urban studies, 1995, 32(3), 551-562. 1998

10. Pumain, D. (1982). La dynamique des villes. Economica. Paris.

11. Schaffar, A. La loi de Zipf dans la science régionale: entre anciennes controverses et nouvelles perspectives. Cybergeo: European Journal of Geography. 2009.

12. Gabaix, X., \& Ioannides, Y. The evolution of city sizes' distribution in Henderson JV et Thisse JF.(eds) Handbook of regional and urban economics, vol. 4. 2004

13. Belhedi, A ; Le système urbain tunisien. Croissance urbaine et système hiérarchique". Revue Tunisienne de Géographie (RTG). 21/22. 1992. pp.177-191.

14. Thouez, J. Study of hierarchy of cities of Quebec as function of their population according to Zipf model. Actualité économique, 1972, 48(3), 519-525.).

15. Pumain, D. Systèmes de villes et niveaux d'organisation.Sanders, L. Regards scientifiques croisés sur la hiérarchie des systèmes de peuplement: de l'empirie aux systèmes complexes. Région et développement, 2006 (36), 127-146.

16. Sanders, L. (2012). Regards scientifiques croisés sur la hiérarchie des systèmes de peuplement: de l'empirie aux systèmes complexes. Région et développement, (36), 127-146.

17. Pumain, D., Sanders L. and Saint-Julien Th. Cities and self-organization. Paris. Economica. 1989

18. Moriconi, Moriconi-Ebrard, F. (1993). L'urbanisation du monde de 1950 à 1990 d'après une définition harmonisée des ag-glomérations urbaines (Doctoral dissertation, Paris 1).

19. Belhedi, A. Le système urbain tunisien. Analyse hiérarchique démo-fonctionnelle sur la base de la loi Rang-taille. Cybergeo: European Journal of Geography. 2004.

20. Belhedi, A. A propos de la loi rang-taille Les impasses d'une mauvaise interprétation. 2001

21. ONS. L'armature urbaine RGPH 2008 /Les principaux résultats de l'exploitation exhaustive / Série S : Statistiques Sociales, , Collections Statistiques n 163, Alger. https://www.ons.dz/IMG/pdf/armature urbaine 2008.pdf, 2011.

22. Prenant, A. Aspects de la croissance urbaine des petits centres urbains en Algérie. E.R.A. 706 du CNRS, Université de Tours et C.I.EM., Université de Poitiers, fasc.3, pp.123-146.

23. Bousmaha, A. Le rôle des petites villes dans le mouvement d'urbanisation en Algérie: le cas de la région centrale du tell de l'est algérien. Sciences \& Technologie. D, Sciences de la terre, 2014, 29-44.

24. Côte, M. L'espace algérien, les prémices d'un aménagement OPU. 1983, Alger, 278p.

25. Kasdallah, N. Dynamiques d'urbanisation des villes intermédiaires au Maghreb (Algérie, Maroc, Tunisie): Effet chef-lieu et perspectives de développement (Doctoral dissertation, Université de Cergy Pontoise). 2013. 
26. Bousmaha, A., Boulkaib, A. \&Chouai S. Croissance et hiérarchie urbaines dans la wilaya de Skikda. In Sustainability and urban planning perspectives, approaches and experiences. Editions: The Arab Democratic Center Berlin - Germany. 2020, VR.3383.6422.B. pp. 314-350.

27. Kaddouri, L. Structures spatiales et mises en réseaux de villes pour la régionalisation des territoires (Doc-toral dissertation, Université Paul Valéry-Montpellier III), 2004.

28. Bousmaha, A., Boulkaibet, A. Planification foncière et espaces agricoles périurbains en Algérie. Le cas de l'agglomération de Skikda. Développement durable et territoires. Économie, géographie, politique, droit, sociologie, 2019, 10 (3). 